\title{
The mechanics of first order splay faulting: The strike-slip case
}

\author{
Christopher H. Scholz*, Ryosuke Ando ${ }^{1}$, Bruce E. Shaw
}

Lamont-Doherty Earth Observatory, Palisades, NY, USA

\section{A R T I C L E I N F O}

\section{Article history:}

Received 11 February 2009

Received in revised form

24 August 2009

Accepted 7 October 2009

Available online 14 November 2009

\section{Keywords:}

Faulting

Earthquakes

Fault interactions

\begin{abstract}
A B S T R A C T
First order splay faults, as defined here, are secondary faults that form at acute angles symmetrically on either side of a primary fault of the same sense of shear. We show that these faults form when the primary fault becomes critically misaligned with the principal stresses such that splay fault formation, on the optimum plane for faulting, is favored. First order splay faults, in distinction from other splay faults, are secondary only in the temporal sense - they are subsequent but not subordinate, in a tectonic sense, to the primary fault. Here we analyze the case of strike-slip faults, and compare it with data for several continental transform fault systems, where we show that the splay faults form in the most favorable direction: parallel to the plate motion vector. We also discuss and speculate on several outstanding problems with regard to first order splay faults: the placement of them in space, means by which primary faults become misoriented in the stress field, and the mechanics of first order splay faultprimary fault junctions, once formed.
\end{abstract}

(c) 2009 Elsevier Ltd. All rights reserved.

\section{Introduction}

The term 'splay fault' is common in the literature, but it is usually used in a casual sense to refer to any secondary fault that diverges from another at an acute angle. While there are a variety of secondary faults that might fit that simple description, here we define first order splay faults in a more restrictive way.

This work is motivated by a systematic study of branching within the San Andreas fault system (Ando et al., 2009). In that study we found a dominance of fault junctions of a generalized " $y$ " shape (Fig. 1, inset). If we call the long branch of the " $y$ " the primary fault and the short branch the splay we found that the angle between them showed a well-defined distribution as shown in Fig. 1. The distribution is mirror symmetric: the same distribution of splay angles is found for left (negative angle) and right (positive angle) splays. Within each type of splay, right or left, the distribution is strongly skewed with the peak value near the lower limit. This suggests that the splay formation mechanism has a welldefined minimum angle but a poorly defined maximum. In both cases the peak value of the splay angle is about $17^{\circ}$ (see Ando et al. (2009) for a more detailed analysis). Because the San Andreas fault was continuously active during the formation of the branches shown in Fig. 1, we note that during the formative stage primary

\footnotetext{
* Corresponding author.

E-mail address: scholz@ldeo.columbia.edu (C.H. Scholz).

1 Now at Geological Survey of Japan, National Institute of Advanced Industrial Science and Technology, Tsukuba, 305-8567, Japan.
}

and splay faults were concurrently active. For the San Andreas system, the numbers of right and left splays are approximately equal. These splay faults, such as the San Jacinto, Calaveras, and Hayward faults, though secondary, in the sense that they formed after the formation of the San Andreas fault, are of first order; they are of the same order of magnitude as the San Andreas in terms of their length, slip rate, or net slip.

These well-defined properties of what we have called first order splay faults suggest to us that we have isolated a set of secondary faults that must share a common mode of origin. It is the purpose of this paper to explore that mode of origin. To begin, in order to differentiate what we wish to call a first order splay fault from all other species of secondary faults, some of which have also been called splay faults, we need to offer a definition of what we mean by a first order splay fault. We start with a precise definition as shown in Fig. 1 (inset). Later, when we have offered a mechanical model for their origin, this definition becomes more restrictive.

The first order splay faults in Fig. 1 have purposefully been drawn as not meeting the primary fault because it is shown later that they do not, in general, do so. However, if the splay fault is projected to meet the primary fault, it will define a line of intersection. We then can make our definition.

Definition: For any fault to be called a first order splay fault its sense of shear must be the same as the primary fault, the respective slip vectors must lie in the plane perpendicular to the line of intersection of the two faults, its slip vector must lie symmetrically at an acute angle on either side of that of the primary fault, and both faults must be concurrently active at the 


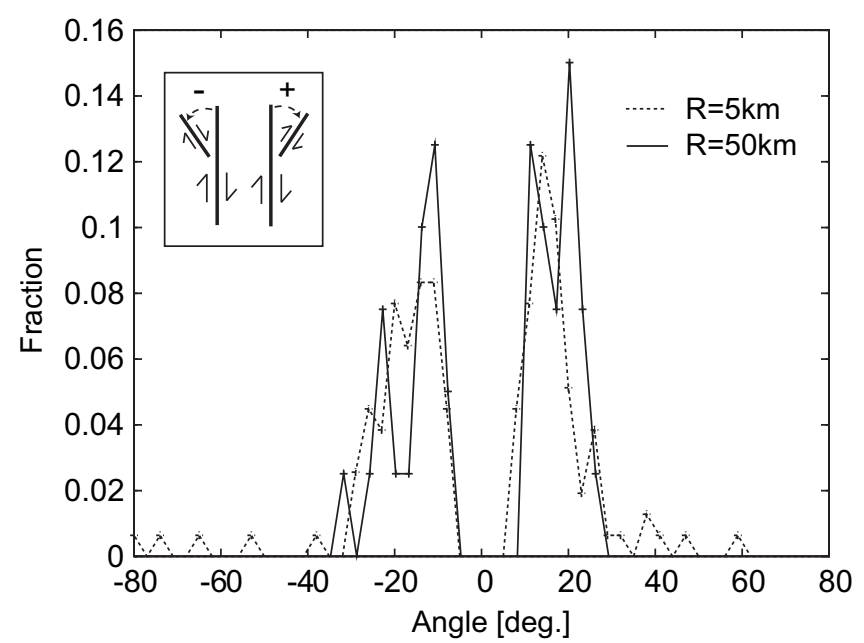

Fig. 1. Histogram of splay faults of the San Andreas fault system, from Ando et al. (2009). The geometry of the splays is shown in the inset, right splays are given positive angles, left splays, negative. The splay angle distribution was found to be independent of $R$, the scale length used in fitting the faults. Two extreme values of $R$ are shown in the figure.

time of formation of the splay fault. They must also be of the same order as the primary fault, in terms of length, slip rate, or total slip.

The first thing to say about this definition is that it does not specify the direction of the line of junction; thus it can apply to strike-slip, normal, thrust faults, or anything in between. Here, however, we will be concerned only with strike-slip cases. Most studies of secondary faults have been of those that are produced by and restricted to the regions of stress concentration associated with fault tips, jogs, and other geometric irregularities. (e.g. de Joussineau et al., 2007; Du and Aydin, 1995; Kim and Sanderson, 2006; Martel and Boger, 1998). Because such secondary faults are restricted to the region of stress concentration they are of second order with respect to the primary fault. Some of these have been called splay faults, but they do not fit our definition of first order splay faults. De Joussineau et al. (2007), for example, used the term splay to refer to 'wing' cracks, which are opening mode cracks that form 'horsetails' on the extensional sides of mode II fault tips. Although these may be later reactivated in shear and thus be called faults, they are asymmetric with respect to the primary fault, they do not originate as faults, and they are of second order. Reidel shears, a form of secondary fault that is not tip-related (e.g. Freund, 1974), are also eliminated because they are asymmetric with respect to the sense of shear. The statement 'same shear sense' also eliminates conjugate faults and various types of antithetic faults. The statement 'concurrently active' eliminates junctions of faults that may have formed during different tectonic episodes.

There have been various efforts at modeling fault branching. Du and Aydin (1995) considered the effect of the orientation of the remote tectonic stresses on the propagation of a strike-slip fault. They found that if the maximum compressive stress $\sigma_{1}$ makes an angle with the fault greater than $45^{\circ}$ with a right-lateral strike-slip fault, the fault would bend into the extensional side of the fault tip (positive angle in terms of Fig. 1) at an angle proportionate to the degree to which the angle of $\sigma_{1}$ exceeds $45^{\circ}$. Conversely, if the $\sigma_{1}$ direction is less than $45^{\circ}$ the bend would be into the compressional quadrant (negative). (That the neutral angle at which the fault does not bend is $45^{\circ}$ rather than, say, the Coulomb angle results from the particular failure criterion they assumed, that of maximum distortional strain energy, in which the normal stresses are squared so that compression and tension are not discriminated.) Their model does not define a minimum bend angle, as the results of Fig. 1 would require, because they choose to deal with locations near the tips of pre-existing faults where stress perturbations are strong; the effect of this perturbation is dominant only near these tips, at greater distances the remote tectonic stress becomes predominate.

These modeling results suggest that the response of the fault tip to variations of tectonic stress direction will be a fault bending rather than branching. Although we point out some examples of this behavior later, branching at the fault tip does not appear to explain, in general, the formation of first order splay faults.

Poliakov et al. (2002) studied the problem of branching resulting from the dynamic stresses associated with earthquake propagation. Because the end of the earthquake may be well away from the physical end of the fault, this problem considers branching from the stem of the primary fault, which seems more relevant to our problem. They found that such branching is influenced by the remote tectonic stress direction but that this was asymmetric: for a given deviation of $\sigma_{1}$ from the neutral direction, the favored branch on the extensional side had a greater angle than one on the compressional side. This difference from the Du and Aydin (1995) results is because Poliakov et al. (2002) assumed a frictional failure criterion for the fault branches.

These results are instructive, but they assumed cohesionless (i.e. pre-existing) branches. The effect of pre-existing branches, jogs, and other geometrical irregularities on earthquake propagation is an important problem in earthquake mechanics and has therefore attracted considerable interest (e.g. Bhat et al., 2004, 2007; Duan and Oglesby, 2007). It is not, however, our problem, which is the initial formation of first order splay faults in cohesive rock.

All the modeling studies of fault branching reviewed above assume that the branch fault nucleates in the stress concentration associated with the fault or earthquake tip or some other geometrical irregularity of the primary fault. All such cases predict that the secondary fault initiates at the primary fault and propagates away from it. We point out later that there is a considerable spatial gap between the primary fault and the nearest tip of first order splay faults, which are best interpreted as having nucleated at a distance from the primary fault and then propagated towards it. This observation greatly simplifies our problem, because it means that we can ignore stress concentrations associated with the primary fault and pose the problem entirely in terms of the regional tectonic stresses.

\section{A criterion for first order splay fault initiation}

The term 'branching' was used in the introduction in a geometric, not genetic sense. However, the terms primary and secondary faults were used with care, to indicate that one pre-existed the other. These are essential to what follows.

\subsection{Failure criterion for first order splay faulting}

We propose that first order splay faults form when the primary fault is sufficiently misoriented with respect to the stress field that it becomes favorable to form a new fault in the optimal orientation; this is the splay. This situation is illustrated in Fig. 2 with a Mohr diagram, in which there are two failure criteria: a frictional one for sliding on a pre-existing fault, and a Coulomb criterion, with cohesion $\tau_{0}$, for the formation of a new fault. Let us suppose that the primary fault has become misoriented with respect to the principal stresses (there are various ways that this can happen, discussed in a later section). This is represented as a rotation of the fault, either to the right or left, on the Mohr circle, as shown in the inset to Fig. 2. As the fault rotates in the stress field, in order for the primary fault to remain active, the stress difference $\left(\sigma_{1}-\sigma_{3}\right)$ must increase, as shown 


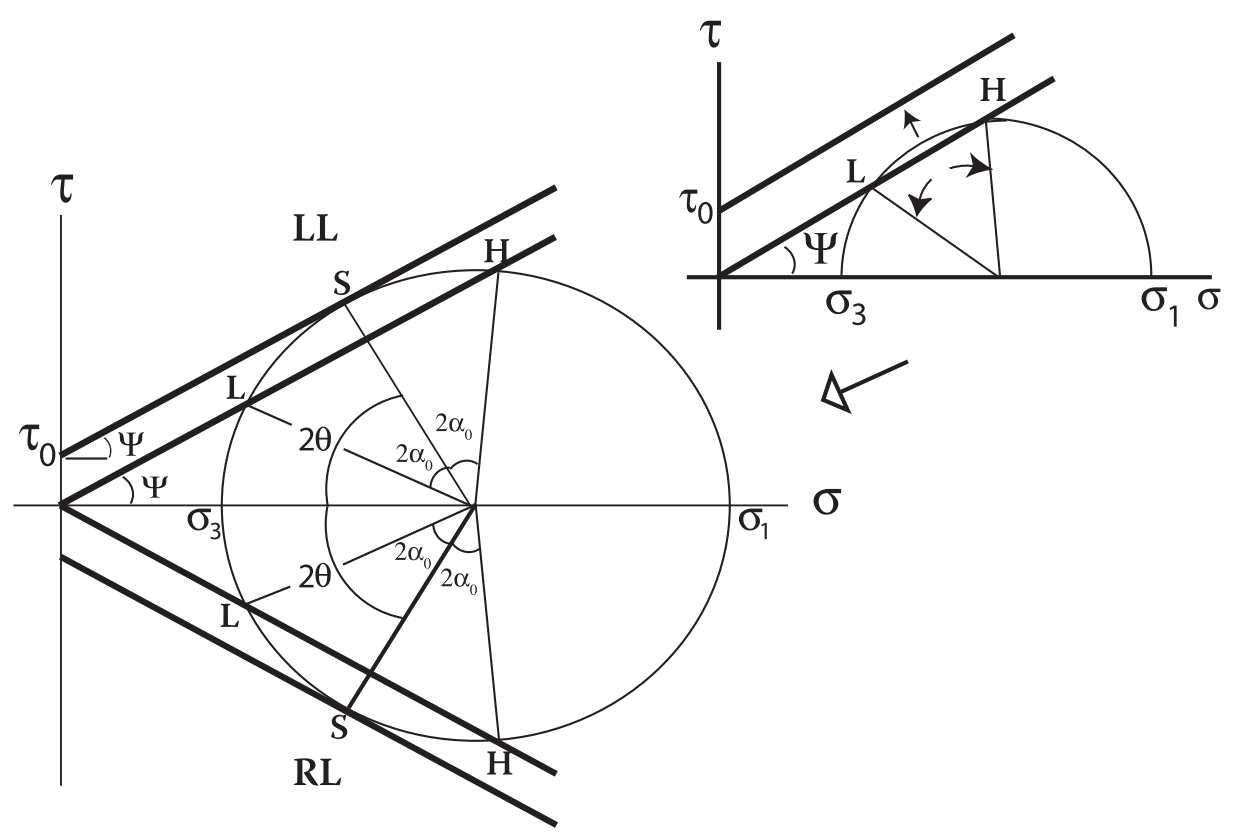

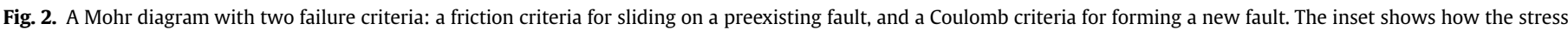

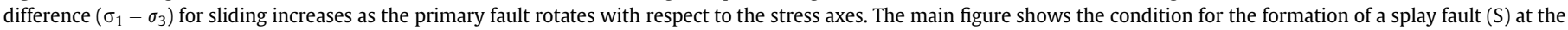

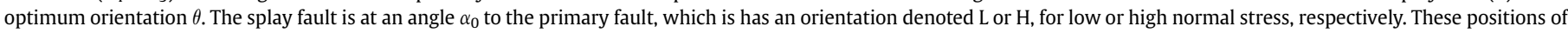
the primary fault define $\mathrm{L}$ - or $\mathrm{H}$-splays.

in the inset. At a critical degree of misorientation, when the primary fault is at the positions $\mathrm{L}$ or $\mathrm{H}$, as shown in the main part of Fig. 2, the Coulomb criterion becomes satisfied and a first order splay fault $(S)$ is formed at the optimum angle $\theta$. In this illustration, we have assumed that the friction angle $\psi$ is the same for both friction and faulting; this is required by the symmetry observed in Fig. 1.

If we suppose that Fig. 2 represents strike-slip faulting, then the lower semi-circle shows the right-lateral case, which corresponds to the data in Fig. 1. We see that there are two critical misorientations of the primary fault for the formation of a splay, which we denote $\mathrm{H}$ (for high normal stress) and L (for low normal stress). For both cases, the critical splay angle $\alpha_{0}$, the angle between the primary fault and the splay fault at splay formation, is equal; it is a right splay in the first case and a left splay in the second. If we shift attention to the left-lateral case (upper semi-circle) we notice that the sign of the splay (right or left) switches for the $\mathrm{H}$ and L cases. Therefore the sign of the splay is not fundamental; what is fundamental is the type of splay, $\mathrm{H}$-splay or L-splay, corresponding to the $\mathrm{H}$ or L orientation of the primary fault at splay formation. We emphasize that the $\mathrm{H}$ and $\mathrm{L}$ positions are not at the frictional lock-up angle. The lock-up angle is $2 \theta$ (Sibson, 1985), and except for the special case when $\sigma_{3}=0$, $\alpha_{0}<\theta$, so the splay fault will form before the primary fault reaches the lock-up angle. Thus the primary fault will be active, and generally remain active, after the splay fault forms, thus satisfying the "concurrently active" stipulation in our definition.

This criterion satisfies our definition of first order splay faults. It also allows us to make the following propositions, which if demonstrated to be correct, place additional restrictions on our definition.

1. First order play faults form when the primary fault becomes misoriented with respect to the principal stresses by a critical angle $\alpha_{0}$.

2. First order splay faults form (a) in the optimum direction for faulting and (b) at an angle $\alpha_{\mathrm{o}}$ from the primary fault.

3. Although secondary in a temporal sense, first order splay faults need not be of lesser rank than their associated primary fault; they are subsequent but not subordinate.
The first proposition means that, unlike secondary faults that are generated by fault tip stresses, splay faults are not ubiquitous. The third proposition arises because the first order splay fault is driven by regional stresses, not by stress concentrations associated with the primary fault. Thus, although secondary in the sense of time of formation, first order splay faults are not necessarily subordinate in the sense of being tectonically inconsequential with respect to the primary fault. This is the main distinction of first order splay faults from secondary faults driven by localized stresses such as the fault tip stresses of the primary fault, as in the case of wing cracks, which de Joussineau et al. (2007) show are consequently always a fraction of the length of the primary fault.

For the case illustrated in Fig. 2, it can be shown that the expression for the critical angle for splay formation, $\alpha_{0}$ is

$\alpha_{0}=\sin ^{-1}\left[\frac{\tau_{0}}{\left(\sigma_{1}-\sigma_{3}\right)} \cos \psi\right]^{1 / 2}$.

From this we see that $\alpha_{0}$ decreases with stress difference $\left(\sigma_{1}-\sigma_{3}\right)$. Thus as the primary fault rotates, the condition for splay faulting will be first met at the base of the brittle layer, where the stress difference is highest. The thickness of the brittle layer, $h$, is somewhat greater than the seismogenic depth (Scholz, 1988) and can be approximated from geodetic data as the 'locking depth' (Savage and Burford, 1973). Once nucleated, the splay fault will propagate in its plane, driven by its fault tip stress concentrations.

In Fig. 3 we show calculated values of $\alpha_{0}$ plotted vs. brittle depth $h$ for Barre Granite (BG) and Westerly Granite (WG), two experimentally well-studied rocks that we take to be representative of the continental crust. Stress difference $\left(\sigma_{1}-\sigma_{3}\right)$ vs. $h$ was extrapolated from the standard stress-depth profile from deep borehole stress measurements (Townend and Zoback, 2000; Zoback and Zoback, 2007). The friction coefficient $\mu=0.6$ and the associated angles $\psi=30^{\circ}$ and $\theta=30^{\circ}$ were obtained from the same data.

The uniaxial compressive strength $C_{0}(t)$ as a function of load duration $t$ is given by a simple static fatigue law $C_{0}(t)=A-B \log t$. Using data from Kranz (1980), we calculated $C_{0}$ for a load duration of 


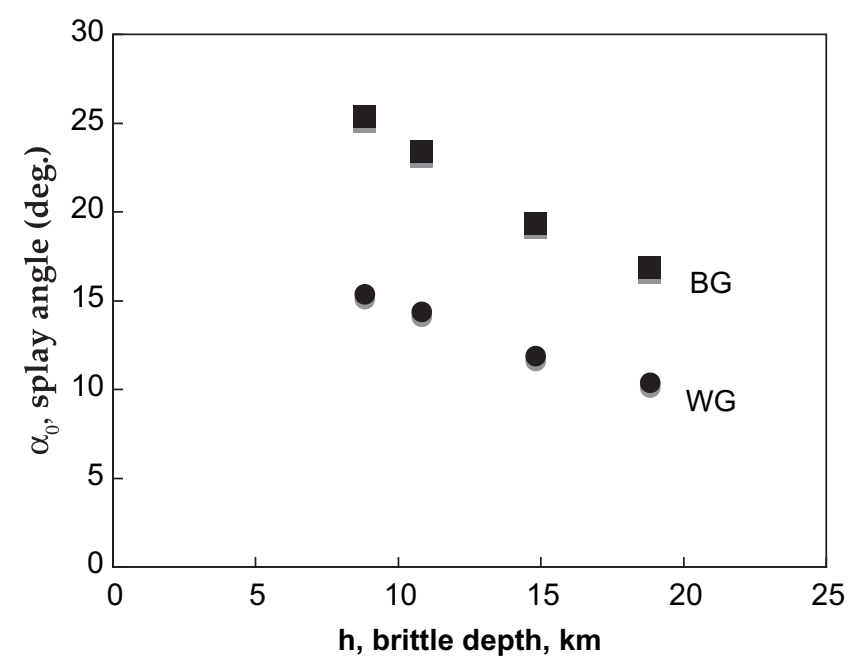

Fig. 3. The critical splay angle $\alpha_{0}$ calculated, using Eq. (1), as a function of brittle depth $h$ for two well-studied rock types: Barre granite (BG) and Westerly granite (WG).

$10^{5}$ years to be $48 \mathrm{MPa}$ and $109 \mathrm{MPa}$ for Westerly Granite and Barre Granite, respectively. Using the relationship $C_{0}=2 \tau_{0}\left[\left(\mu^{2}+1\right)^{1 / 2}+\mu\right]$ (Jaeger and Cook, 1976) and $\mu=0.6$ gives the corresponding values of $\tau_{0}$ to be 14 and $30 \mathrm{MPa}$, which were used for the calculations shown in Fig. 3. These estimates are relatively insensitive to the loading duration assumed. If we assume $10^{6}$ years, the angles in Fig. 3 would be increased by an average of about $1.5^{\circ}$. Taking $10-15 \mathrm{~km}$ to be common estimates of the brittle thickness, the results shown in Fig. 3 bracket the expected value of $\alpha_{0}$ to be between 12 and $22^{\circ}$.

\subsection{Comparison of theory with observation}

The initial test of our model, noted above, is that it agrees with our geometric definition of first order splay faults. We now compare the quantitative results with the observations of strikeslip splay angles $\alpha$. We discriminate between the critical angle $\alpha_{0}$ given by the theory and the observed angles $\alpha$ because the former refers to the angle at the time of splay formation whereas the latter may include any rotation between the primary and splay faults that has occurred following splay nucleation.

\subsubsection{Data from Ando et al. (2009)}

The data from Ando et al. (2009) are shown in Fig. 1. The peak values of the $\alpha$ distributions of $\sim 17^{\circ}$ are well bracketed by the calculated range of Fig. 3. The sharp lower cut-off in the data is consistent with the model in the sense that the critical value $\alpha_{0}$ is a minimum value. The model predicts an upper cut-off when the primary fault is at the lock-up angle $2 \theta$. At that point $\alpha_{0}=\theta \approx 30^{\circ}$, which agrees with the upper cut-off observed in Fig. 1. Both right and left splays are present for this right-lateral strike-slip fault because the San Andreas, far from being straight, has portions along its length in which its strike departs markedly, in both signs, from the plate motion vector (Gilbert et al., 1994). This results in the formation of both $\mathrm{H}$ and $\mathrm{L}$ type splays. The fact that the San Andreas fault has an almost equal number of right and left splays is, within the framework of this model, a coincidence.

These data are consistent with proposition $2 \mathrm{~b}$, but in order to fully test proposition 2 and proposition 1, we need to examine currently active crustal scale splay faults for which there is some independent knowledge of the optimum faulting direction or principal stress orientation. In the case of strike-slip faults, if the fault is a transform fault, it is then reasonable to suppose the optimum faulting direction is parallel to the direction of relative right-lateral transform fault case (map view)

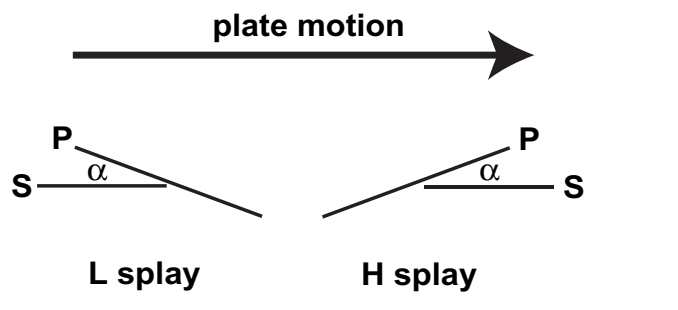

Fig. 4. Configurations of active splay-primary fault pairs used in testing the model. A transform fault in map view. The optimum faulting plane is taken to be strike in the plate motion direction. The orientations of primary (p) and splay (s) fault are shown for the $\mathrm{H}$ and $\mathrm{L}$ type splay formation modes.

plate motion, and that splay faults will accordingly form in that direction. Under displacement boundary conditions, such as imposed by plate tectonics, displacement is the independent variable and stress is the dependent variable. Stresses will therefore become adjusted to the displacements in accord with the appropriate constitutive law, which in the case of brittle fracture is the Coulomb criterion. The plate motion direction therefore must also be the optimum direction in terms of stress orientation, and so we can relate this to the stress fracture criterion as shown in Fig. 2.

In Fig. 4 we illustrate both the $\mathrm{H}$ - and L-splay situations for a right-lateral transform fault, such as the San Andreas. In each case, the expected splay is shown to form parallel to the plate motion vector.

\subsubsection{Active strike-slip splay faults}

We studied active crustal scale splay faults for three continental transform faults, the San Andreas fault of California, the Alpine fault of New Zealand, and the Denali fault of Alaska. The data for California are from (Bryant, 2005) and for New Zealand, http://data. gns.cri.nzaf/. The Denali fault and its splay the Totschunda fault were recently highlighted by the M 7.8 Denali fault earthquake of 2002, which propagated to the east along the Denali fault for several hundred kilometers and then transferred to the Totschunda fault where it propagated for an additional $65 \mathrm{~km}$ (Haeussler et al., 2004). For that case we use the fault map as illuminated by the earthquake rupture (Haeussler, 2009). The faults themselves, of course, long pre-existed the earthquake rupture.

The splay junctions to be discussed are highlighted in Fig. 5. Each junction was fit to a $\mathrm{Y}$ shaped test function, as described in Ando et al. (2009). The identification of the primary faults is obvious except in the case of the San Gregorio fault. That fault, with a net slip of $180 \mathrm{~km}$, predates the youthful San Francisco peninsula segment of the San Andreas fault, which dates from only 2 Ma and has a net slip of just $20 \mathrm{~km}$ (Wakabayashi, 1999). For their junction, the San Gregorio fault is the primary fault.

The results are given in Table 1 . The clockwise angle between the plate motion vector and the primary and splay faults are $\phi_{\mathrm{p}}$ and $\phi_{\mathrm{s}}$, respectively, and the splay angle is $\alpha$. The parameter $R$ is the length scale over which the faults are fit to determine their strike (Ando et al., 2009). The plate motion vectors, shown in Fig. 5 are, for California and New Zealand from NUVEL 1A (Demets et al., 1994). For the Alaskan faults the reference is to the Yakutat microplate (Fletcher and Freymueller, 2003). The results are shown as histograms in Fig. 6.

The splay faults strike considerably closer (avg. $6^{\circ}$ ) to the plate motion direction than do the primary faults (avg. $19^{\circ}$ ). The splay angles vary between $9^{\circ}$ and $21^{\circ}$ (avg. $14^{\circ}$ ). In most cases (7 vs. 3, 1 neutral) the splay fault appears to have been rotated away from the plate motion vector in the same sense as the primary fault. This suggests that the rotation that caused the original misalignment of 

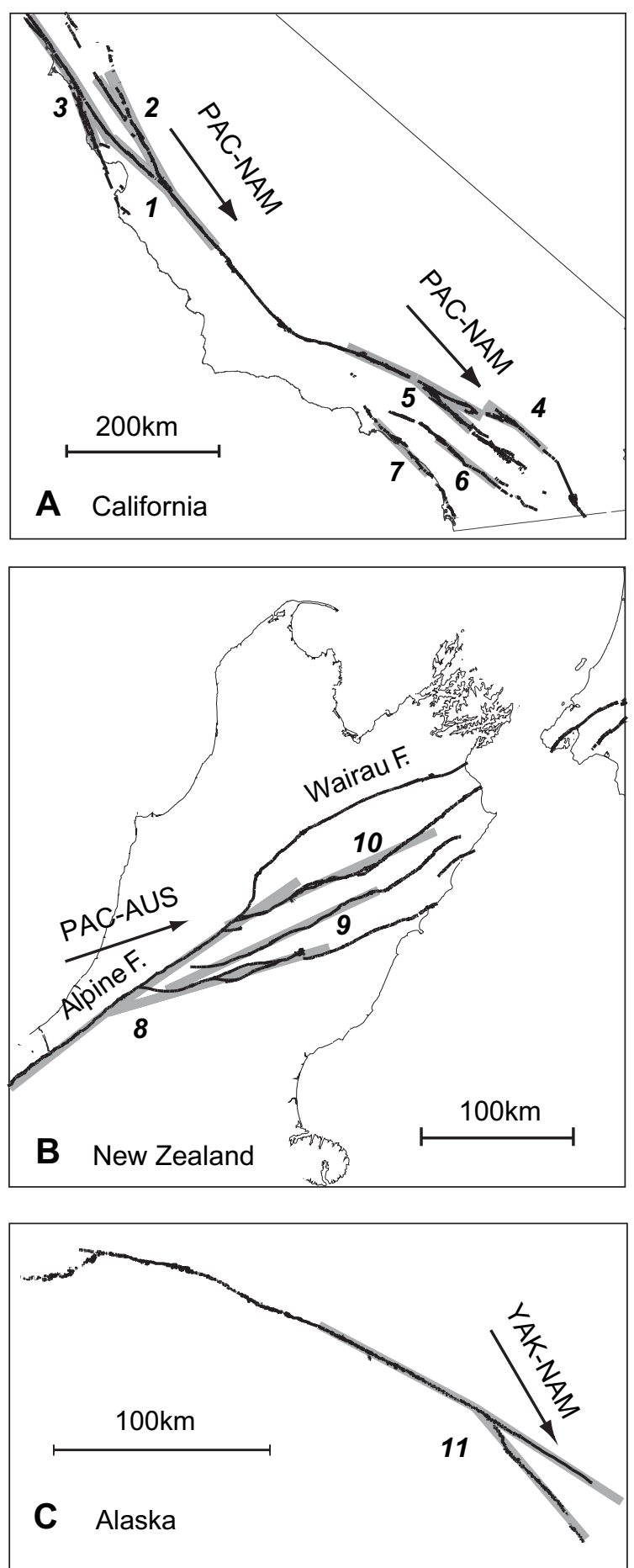

Fig. 5. Maps of the continental transform faults studied. Each splay junction is highlighted and numbered. The numbers are keyed to Table 1 . Data sources are given in the text. Plate motion vectors are shown: the first plate listed is the reference plate.

the primary fault continued after the formation of the splay fault, thus subsequently rotating both faults away from the plate motion direction. This has been independently argued to be the case for the splay faults of the Alpine fault, collectively known as the Marlborough faults (Fig. 5b). There, the nearby Australian/Pacific pole of rotation migrated, first changing the slip vector from transcurrent to transpressive on the Alpine fault, resulting in the formation of the Marlborough faults, then continued to migrate so that those faults in turn became transpressive (Little and Jones, 1998; Walcott, 1998).
Table 1

Major splays of the San Andreas, Alpine and Denali faults.

\begin{tabular}{|c|c|c|c|c|c|c|c|}
\hline \multirow[t]{2}{*}{ No. in Fig.4 } & \multicolumn{2}{|l|}{ Fault name } & \multicolumn{3}{|c|}{ Angles $\left({ }^{\circ}\right)$} & \multirow[t]{2}{*}{ Splay type } & \multirow{2}{*}{$\frac{\text { Length }}{R(\mathrm{~km})^{\mathrm{b}}}$} \\
\hline & Primary & Splay & $\phi_{\mathrm{p}}$ & $\phi_{\mathrm{s}}$ & $\alpha$ & & \\
\hline 1 & San Andreas & Calaveras & -14 & 7 & 21 & $\mathrm{H}$ & 100 \\
\hline 2 & Calaveras & Hayward & 9 & -3 & 12 & $\mathrm{~L}$ & 100 \\
\hline 3 & San Gregorio & Peninsula S.A. & 12 & 0 & 12 & $\mathrm{~L}$ & 100 \\
\hline 4 & San Andreas & Coachella S.A & -22 & -11 & 11 & $\mathrm{H}$ & 50 \\
\hline 5 & San Andreas & San Jacinto & -21 & -8 & 13 & $\mathrm{H}$ & 100 \\
\hline 6 & San Andreas & Elsinore & -20 & -10 & 10 & $\mathrm{H}$ & $100^{c}$ \\
\hline 7 & San Andreas & NIRC & -21 & -5 & 16 & $\mathrm{H}$ & $100^{c}$ \\
\hline 8 & Alpine & Hope & -15 & 2 & 17 & $\mathrm{H}$ & 150 \\
\hline 9 & Alpine & Clarence & -17 & -8 & 9 & $\mathrm{H}$ & $150^{c}$ \\
\hline 10 & Alpine & Awatere & -18 & -8 & 10 & $\mathrm{H}$ & $150^{c}$ \\
\hline 11 & Denali $^{\mathrm{a}}$ & Totschunda & -27 & -10 & 17 & $\mathrm{H}$ & 80 \\
\hline
\end{tabular}

The angles $\phi_{\mathrm{p}}$ and $\phi_{\mathrm{s}}$ are the angles of the primary and splay faults measured clockwise from the estimated plate motion vector from NUVEL 1A (Demets et al., 1994) except the Denali/Totschunda case. The splay angle is $\alpha$ and the splay type $\mathrm{H}$ (high), L (low), is as shown in Fig. 2. NIRC, Newport-Inglewood Rose Canyon fault.

a Since there is considerable uncertainty of the plate motion vector, the GPS observed velocity on the nearby Yakutat microplate against the stable North American plate is used from Fletcher and Freymueller (2003). Alternatively, the angles are calculated as $\phi_{\mathrm{p}}=-43, \phi_{\mathrm{s}}=-26$ PAC/NAM by DeMets and Dixon (1999). Note that the splay is more aligned with the plate motion than the primary in either model.

b The length $R$ is each leg length of the "Y" shaped test function implemented in the computer-based analysis (see Ando et al., 2009, for the method), in which the value is chosen to fit with the trend of fault traces as shown in Fig. 4; the gray lines indicate the fitted test functions. A larger $R$ value is used in the Alpine fault system to down-weight the near fault region, where fault traces are inferred rather than observed.

c The "I" shaped test function with one leg is used instead of "Y" to avoid relatively large gaps to the San Andreas fault for the Elsinore and Newport-Inglewood Rose Canyon fault cases, and the offset of the Alpine fault below the Spenser mountains north of the splay junctions for the Hope and Clarence faults case.

These results provide deeper support for our hypothesis than those of Fig. 1. They lend strong support to all the particulars of propositions 1 and 2 regarding the orientations of both the primary and slay fault with regard to the plate motion directions at the time of splay formation. They also support proposition 3, since none of the splay faults can be considered to be minor in importance with respect to their associated primary faults.

\subsection{Summary of results}

We have presented a very simple model for the formation of first order strike-slip splay faults. This model successfully predicts the observed angular relation of these splays with primary faults and the orientation of both with respect to the plate motion directions at the time of splay formation. The examples given suggest that first order spay faults are a common form of secondary faults. Unlike other secondary faults, first order splay faults are not necessarily minor in comparison with their associated primary faults.

\section{Discussions and speculations on outstanding problems of first order strike-slip splay faulting}

The criterion presented above explains the existence of first order strike-slip splay faults, the condition of the primary faults for their formation, and their orientation with regard to the primary fault and the plate motion direction. It remains, however, a onedimensional solution. The Mohr circle represents stress at a point, and using it to represent stress in a region is equivalent to assuming that stress is uniform within that region. This is an obvious simplification, and it is gratifying that the theory works as well as it does, though not entirely surprising. The success of the Coulomb criterion in explaining regional fault orientations, demonstrated long ago by Anderson (1951), is based on the same assumption. 

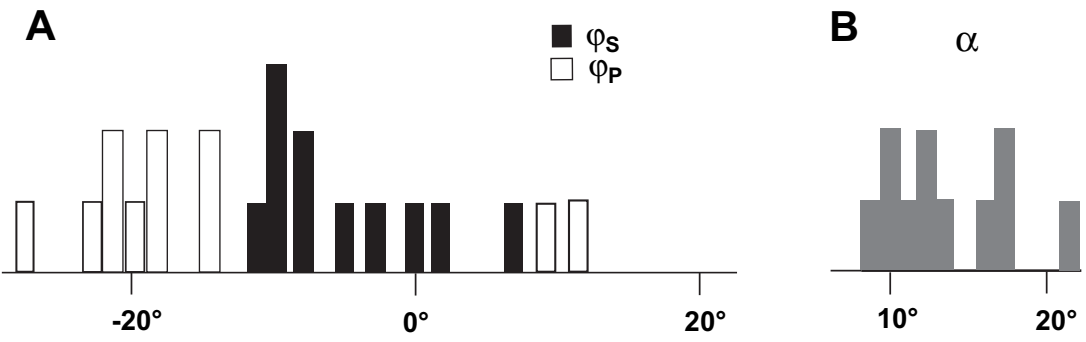

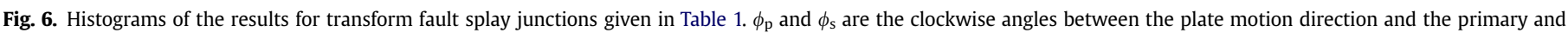
splay fault, respectively. $\alpha$ is the angle between the splay and primary fault.

The World Stress Map Project has largely validated that assumption. One of its main findings was that "Stress orientations are remarkably uniform over broad regions (length scales up to thousands of kilometers), despite large changes in crustal geology, tectonic history, and crustal thickness" (Zoback and Zoback, 2007). Hardebeck and Hauksson (2001) found that, at the largest scale, stress directions are homogeneous over southern California, but they are heterogeneous at small to medium scales. Much of that heterogeneity results from perturbations produced by the major faults (Hardebeck and Hauksson, 1999; Scholz, 2000) and would not have existed prior to the formation of those faults (the period in which we apply the assumption of homogeneity). The very regular pattern of faulting produced (Fig. 5) belies the notion that, at the large scale, they are governed by pre-existing heterogeneities in stress or strength. Indeed, it has long been noticed that the fault systems of southern California and the South Island of New Zealand, when viewed from the perspective of their plate motion directions, almost overlay one another (Scholz, 1977; Yeats and Berryman, 1987), which strongly argues against these systems being strongly dependent on local conditions.

Nonetheless, this criterion fails to address many other problems regarding first order splay faults. The principal problems fall into three main categories: the placement of first order splay faults in space, means by which primary faults become misoriented in the stress field, and the mechanics of splay-primary fault junctions, once formed. The solutions to these problems are, in some cases, beyond our present capabilities, but we feel it worthwhile to state these problems and offer some speculation as to what their solutions may be.

\subsection{The placement of first order splay faults}

\subsubsection{Proximal or distal splay nucleation, and their spacing}

We earlier reviewed several models that propose that splay faults branch from either the end or the stem of the primary fault when the tectonic stress direction becomes unfavorably oriented with respect to the primary fault. Let us call this the proximal hypothesis.

In New Zealand, the Alpine fault at its northern end is mapped as continuous with the Wairau fault, the northernmost of the Marlborough faults. This appears to be a case of the fault bending at its tip, as envisioned in the model of Du and Aydin (1995). Although complicated by several other smaller splays, the Coachella branch of the San Andreas fault may have also formed in the same way. In the other cases, however, several lines of evidence lead us to suspect that the opposite is true, that splays nucleate at some distance from the primary fault and subsequently propagate bilaterally, both towards and away from the primary fault. Call this the distal hypothesis.

A prima facie case against stem branching is that in the other cases examined in Fig. 5 splay faults are not found to contact the primary fault - although they are sometimes mapped as 'inferred' to do so.

As crustal scale strike-slip splay faults approach the primary fault they are usually observed to gradually disappear, presumably as their slip goes to zero, some kilometers to 10s of kilometers from the primary fault, where their terminations are often accompanied by complex branching and the formation of other structures, such as folds, that indicate a complex stress condition near the junction of the faults. They are also never observed to offset the primary fault, which would be the case if they abutted it and then accrued finite displacement. In several cases, such as the Elsinore and Clarence faults (Fig. 5a,b), their proximal ends terminate unambiguously far from the primary fault.

The crustal scale splay faults of California and New Zealand (Fig. 5a,b) form arrays of parallel, nearly equally spaced faults. Their spacing of $\sim 30 \mathrm{~km}$ suggests that they form just outside the stress shadow of the adjacent splay. The stress shadow of a strike-slip fault extends out about one fault depth on either side (Kostrov and Das, 1984). For the stress shadows of two faults to not overlap, their spacing should be two fault depths. Taking $10-15 \mathrm{~km}$ as the brittle depth for these regions from their estimated locking depths (Bourne et al., 1998; Meade and Hager, 2005), we thus expect a fault spacing of $20-30 \mathrm{~km}$, as observed.

A corollary of this argument is that the splay is inhibited from nucleating within the stress shadow of the primary fault. If these stress shadows control the nucleation position of the splay fault, then splay faults must initiate far from the primary fault and adjacent to a pre-existing splay fault. Otherwise the regular spacing of splay faults cannot be explained.

This particular situation requires that the splay faults form in sequence, with the topmost (with respect to the end of the primary fault) forming first, and then each in turn to the bottom-most. For the Marlborough faults in New Zealand (Fig. 5b), this is exactly what has been proposed by Little and Jones (1998), based on the progressive decrease in net geologic slip on the faults as one proceeds southwards. Thus the net slip of the topmost splay, the Wairau fault, is $140 \mathrm{~km}$, followed, progressing southwards, by the Awatere, $34 \mathrm{~km}$, the Clarence, $18 \mathrm{~km}$, the Hope, $20 \mathrm{~km}$, and the bottom-most, the Porters Pass-Amberley fault (not shown in Fig.5b), $2 \mathrm{~km}$. One can make the same argument for the splay faults in southern California. There the net slip of the San AndreasCoachella fault, the topmost splay, is $185 \mathrm{~km}$ (Dillon and Ehrig, 1993), thence progressing in this case westwards to the San Jacinto, $20 \mathrm{~km}$ (Kendrick et al., 2002), the Elsinore, $12 \mathrm{~km}$ (Magistrale and Rockwell, 1996), and the Newport-Ingelwood-Rose Canyon fault, $3 \mathrm{~km}$ (Freeman et al., 1992).

It seems then, that for the strike-slip case the argument for the distal hypothesis of splay fault formation is most consistent with the observations for all but the topmost faults. Once formed, the splays must propagate bilaterally, with the propagation of the tip back towards the primary fault becoming progressively inhibited as 
the stress shadow of the primary fault is entered. This latter process and its implications are taken up again in a later section.

\subsubsection{An asymmetry and the 'completion' conjecture}

In Fig. 1 it was demonstrated that splay faults are symmetric with respect to primary faults. Yet inspection of our examples indicates that another kind of asymmetry exists. In the case of the Alpine fault (Fig. 5b) the splays form only on the side on which they can connect with the continuing part of the plate boundary, the Hikurangi trough off the east coast of the North Island. They do not form on the opposite side of the Alpine fault. Similarly, the first order splay faults in southern California all occur on the side of the 'big bend' of the San Andreas fault by which they can ultimately link up with the East Pacific Rise in the Gulf of California. There are right-lateral strike-slip faults that occur in the Mojave region on the other side of the big bend, collectively known as the Eastern California Shear Zone, that have the proper orientation for splay faults. However, the estimated slip rates on these faults, $\leq 1 \mathrm{~mm} /$ year (Wesnousky, 1986), are more than an order of magnitude less than the faults we are discussing: hence they are second order faults. These faults may have originated as splays but were stunted because they were not able to link up and become part of the plate boundary. In northern California, the major splays, the Hayward and Calaveras faults, continue, via the Green Valley and Maacama faults, to the Mendocino triple junction.

These observations lead to the conjecture that first order splay faults form only on the side of the principal fault on which they can complete the plate motion circuit (or, in the intraplate case, a circuit to an adjacent fault system). This 'completion' conjecture is not anticipated by our criterion, which predicts that splays may form with equal probability on either side of the primary fault. To understand this feature of splay faulting will require a two- or three-dimensional analysis, which takes into account both the stresses associated with the primary fault and with the 'destination' structure. This is a suggested goal of future work.

\subsection{Mechanisms for misalignment of the primary fault}

The condition for splay fault formation is the misalignment of the primary fault with the regional stress field. Although this topic is outside our immediate purview, it is worthwhile to briefly review the various ways that such misalignment may come about, paying particular attention to the cases that we have used as examples. For a fuller discussion, within the context of strike-slip bends, see Cunningham and Mann (2007) and Mann (2007).

\subsubsection{Original rotation}

Strike-slip bends often form by linking fault step-overs (Cunningham and Mann, 2007). In this case, their misalignment is a feature of their formation. We call this original rotation. Strike-slip restraining and releasing bends are usually too slight or too short to spawn splays, but the 'big bend' of the San Andreas fault, which produced the southern California splays, is an exceptional case. Atwater (1970) proposed that the big bend formed when the southern San Andreas switched from offshore Baja California to inshore with the onset of spreading in the Gulf of California. Its offset may have been further augmented by westward motion, to its north, that accommodated extension in the Basin and Range Province (Scholz et al., 1971). Thus the misalignment of the big bend may have been a consequence of original rotation plus additional misalignment brought about by external conditions.

\subsubsection{Internal or auto-rotation}

An elastic shear crack will rotate in the opposite sense of its shear (Martel, 1999). This results from second couple in the double- couple point source equivalent, so familiar in connection with the earthquake focal mechanism. Such rotations are infinitesimal, but, when the faults are unbounded, as in forming block boundaries with other faults, they may become finite. This is so-called dominoor bookshelf-style faulting, and it has a rich literature (e.g. Anders et al., 1993; Cladouhos and Allmendinger, 1993; Garfunkel and Ron, 1985). This type of rotation can be called internal rotation, with respect to the external shear driving it, or auto-rotation with respect to the faults themselves. Important points are that the direction of auto-rotation is always such as to increase the normal stress applied to the fault and its rate is proportional to the slip rate of the fault. It is usually thought that such rotation will continue until fault lock-up occurs (Jackson, 1987; Sibson and Xie, 1998) but here we note that lock-up may be preceded by the formation of H-type splays. In southern California, which is dominated by strike-slip faulting, this type or rotation about vertical axes has been well documented (Jackson and Molnar, 1990; Luyendyk et al., 1985).

\subsubsection{External or stress rotation}

There are cases in which the fault does not rotate, but the regional stress field does. We call such cases external rotation. A good example is the case of the Marlborough faults of New Zealand (Fig. 5b). The Australian-Pacific pole of rotation lies quite close to the South Island of New Zealand, such that a minor movement of the pole can translate into a major change in the local slip vector. Such a pole migration, beginning $\sim 7 \mathrm{Ma}$, caused the plate motion vector to change from parallel the Alpine fault to oblique, in a transpressive sense (Walcott, 1998). This resulted in the Kaikoura Orogeny, the salient features of which are the uplift of the Southern Alps and the formation of the Marlborough faults. As noted earlier, this rotation continued following the formation of the Marlborough faults, so that they now exhibit transpressive behavior themselves, such as in the uplift of the Seaward Kaikoura ranges (Little and Jones, 1998).

\subsection{Mechanics of strike-slip splay junctions}

For the oblique junctions of splay and primary faults the only kinematically compatible configuration is one in which the splay fault 'merges into' the primary, i.e. bends into parallelism with it as they join. However, in the cases we have studied, not only does the splay not 'merge into' the primary fault, but it is appears to terminate without contacting the primary. A particularly wellstudied case, the junction of the San Jacinto and San Andreas faults, is shown in Fig. 7. GPS and Quaternary fault data indicate that to the northwest, the San Andreas fault is slipping at a rate of $\sim 35 \mathrm{~mm} /$ year. South of the junction the slip rate of the San Jacinto fault is $12 \mathrm{~mm} / \mathrm{year}$ and that of the Coachella section of the San Andreas $23 \mathrm{~mm} /$ year (Meade and Hager, 2005; Wesnousky, 1986).

The San Jacinto fault does not coalesce with the San Andreas fault (Morton and Matti, 1993). It splits into several branches, among them the Glen Helen and Lytle Creek faults, that either die out or turn to the west into thrust faults within the San Gabriel Mountains. As discussed earlier, the San Jacinto fault neither contacts nor offsets the San Andreas fault. Thus, there is no direct kinematic transfer of slip from the San Andreas to the San Jacinto fault. Morton and Matti (1993) argued instead that there is a gradual transfer of slip over a $65 \mathrm{~km}$ long zone in which there is complex deformation of the structures shown in Fig. 7. The termination of the San Jacinto fault within the stress shadow of the San Andreas, and its $\sim 20 \mathrm{~km}$ net slip some $100 \mathrm{~km}$ to the south (Kendrick et al., 2002) requires large stress concentrations in the region of the fault tip, and these are reflected in the structures found there. To the northeast of the San Jacinto fault, the triangular $1.7 \mathrm{~km}$ deep San Bernardino basin is actively subsiding, with a $1.2 \mathrm{~km}$ vertical offset at the San Jacinto fault 


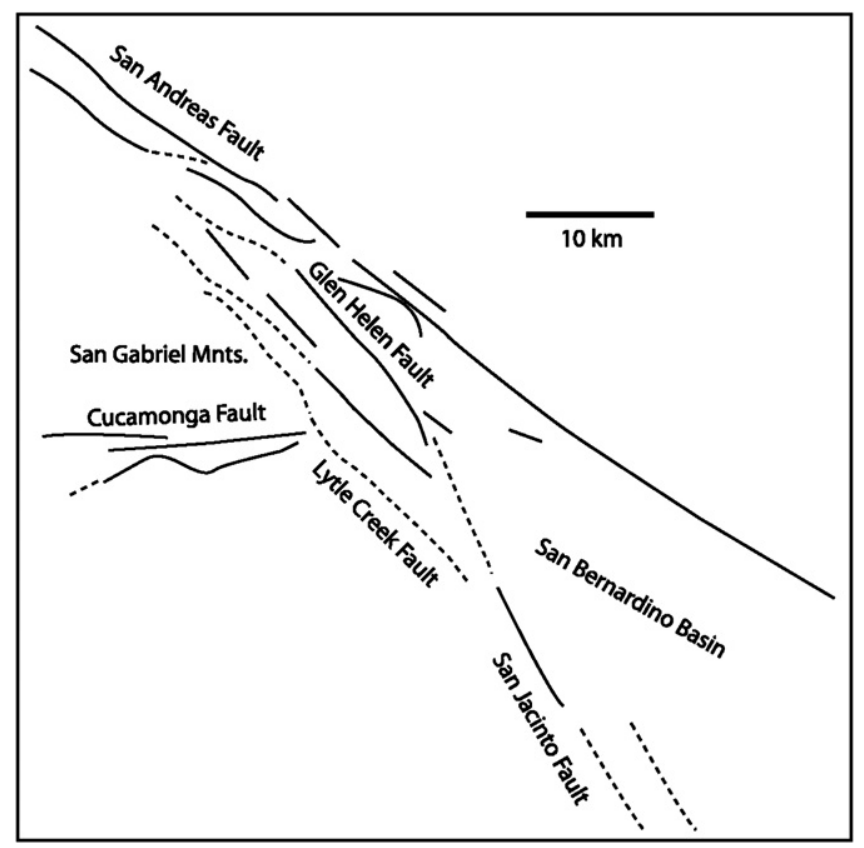

Fig. 7. A map showing the major structural features of the region of the junction of the San Jacinto and San Andreas faults.

(Stephenson et al., 2002). Earthquakes with normal faulting focal mechanisms are common within this basin (Jones, 1988). Just to the west of the terminal section of the San Jacinto fault are the eastern San Gabriel Mountains that are being rapidly uplifted, primarily by thrusting on series of thrusts constituting the Cucamonga fault zone.

Similarly, the Calaveras fault never contacts the San Andreas fault but bends parallel to it, as the Paicines fault, which eventually dies out (Aydin and Page, 1984). Du and Aydin (1995) interpreted this as the Calaveras propagating towards the San Andreas with propagation being inhibited as the San Andreas is approached.

The confluence of the Hope and Alpine faults in New Zealand has a very similar geometry as the San Jacinto/San Andreas junction. A salient feature of that area is an abrupt decrease in the uplift of the Southern Alps just north of the fault junction. On the south side of the Hope fault, in the corresponding position of the Cucamonga fault (Fig. 7), the 1996 M 6.7 Arthur's Pass earthquake occurred. It had a thrust mechanism, dipping in towards the Alpine fault (Abercrombie et al., 2000), evidence for the same tectonic signature as the Cucamonga fault.

These observations suggest that the transfer of slip between primary and splay fault is not, in many case, kinematic but occurs by dynamic coupling. This implies action through the interacting stress fields of active tectonic elements such as faults. This mechanism is now well understood in the case of triggering of earthquakes by prior earthquakes (e.g. Stein, 1999) which often links motion on nearby but non-contacting faults (see also Scholz and Gupta, 2000). An analysis of this type applied to splay/primary fault coupling is beyond our present scope, but is an attractive direction for future studies.

\section{Summary}

We have defined and explained first order splay faults as a class of secondary but not subordinate faults that form when the primary fault becomes sufficiently misaligned with the principal stresses. We have provided a simple quantitative theory for first order splay fault formation and tested it against observational data for strikeslip faults. The results are supportive of all aspects of the theory.
The theory we applied to strike-slip faults is a special case in which the friction angle for sliding on the primary fault is taken to be the same as that for forming the splay fault. This is consistent with the notion that the strength of faults such as the San Andreas is the same as that of other faults in the surrounding crust. Splay faults may form arrays of evenly spaced faults, as shown in the examples from California and New Zealand. These are formed sequentially, with each subsequent fault forming at a distance from its predecessor so as to avoid its stress shadow.

Once a splay fault forms, some portion of the slip of the primary fault is transferred to the splay fault. The mechanism by which that happens is a matter of some contention. For crustal scale strike-slip faults we have found that splay faults usually do not appear to be kinematically linked to their primary fault. This suggests that slip transfer occurs through dynamic coupling, through the action of the stress fields of the faults.

Although we have restricted ourselves here to discussing the case of strike-slip faulting, the mechanics involved are not limited to any particular type of faulting. It is common in subduction zones, for example, for first order splay faults to occur that are concurrently active with their primary faults (Baba et al., 2006; Park et al., 2002; Plafker, 1965). In these cases, the basal thrust (the primary fault) is thought to often have a lower friction coefficient than the splay fault (Suppe, 2007), so that the diagram shown in Fig. 2 would need to be modified accordingly.

\section{Acknowledgements}

We thank Mark Anders, David Wiltschko, and Peter Haeussler for helpful discussions. R.A. was supported by a Japan Society for Promotion of Science Postdoctoral Fellowship in 2005-2007. B.E.S. is supported by NSF grant EAR03-37226, EAR-0911221, and the Southern California Earthquake Center.

\section{References}

Abercrombie, R.E., Webb, T., Robinson, R., McGinty, P.J., Mori, J., Beavan, R.J., 2000. The enigma of the Arthur's Pass, New Zealand, earthquake. 1. Reconciling a variety of data for an unusual earthquake sequence. Journal of Geophysical Research-Solid Earth 105, 16119-16137.

Anders, M.H., Spiegelman, M., Rodgers, D.W., Hagstrum, J.T., 1993. The growth of fault-bounded tilt blocks. Tectonics 12, 1451-1459.

Anderson, E.M., 1951. The Dynamics of Faulting. Oliver and Boyd, Edinburgh.

Ando, R., Shaw, B.E., Scholz, C.H., 2009. Quantifying natural fault geometry: statistics of splay fault angles. Bulletin of the Seismological Society of America 99, 389-395.

Atwater, T., 1970. Implications of plate tectonics for the Cenozoic tectonic evolution of western North America. Geological Society of America Bulletin 81, 3513-3536.

Aydin, A., Page, B.M., 1984. Diverse Pliocene-Quaternary tectonics in a transform environment, San Francisco Bay region, California. Geological Society of America Bulletin 95, 1303-1317.

Baba, T., Cummins, P.R., Hori, T., Kaneda, Y., 2006. High precision slip distribution of the 1944 Tonankai earthquake inferred from tsunami waveforms: possible slip on a splay fault. Tectonophysics $426,119-134$.

Bhat, H.S., Dmowska, R., Rice, J.R., Kame, N., 2004. Dynamic slip transfer from the Denali to Totschunda faults, Alaska: testing theory for fault branching. Bulletin of the Seismological Society of America 94, S202-S213.

Bhat, H.S., Olives, M., Dmowska, R., Rice, J.R., 2007. Role of fault branches in earthquake rupture dynamics. Journal of Geophysical Research-Solid Earth 112 B11309.1-B11309.16.

Bourne, S.J., Arnadottir, T., Beavan, J., Darby, D.J., England, P.C., Parsons, B., Walcott, R.I., Wood, P.R., 1998. Crustal deformation of the Marlborough fault zone in the South Island of New Zealand: geodetic constraints over the interval 1982-1994. Journal of Geophysical Research-Solid Earth 103, 30147-30165.

Bryant, W.A., 2005. Digital database of Quaternary and Younger faults from the Fault Activity Map of California. California Geological Survey Web Page. http://www. consrv.ca.gov/CGS/information/publications/Pages/QuaternaryFaults_ver2.aspx.

Cladouhos, T.T., Allmendinger, R.W., 1993. Finite strain and rotation from fault-slip data. Journal of Structural Geology 15, 771-784.

Cunningham, W.D., Mann, P., 2007. Tectonics of strike-slip restraining and releasing bends. In: Cunningham, W.D., Mann, P. (Eds.), Tectonics of Strike-slip Restraining and Releasing Bends. The Geological Society, London, pp. 1-12. 
de Joussineau, G., Mutlu, O., Aydin, A., Pollard, D.D., 2007. Characterization of strikeslip fault - splay relationships in sandstone. Journal of Structural Geology 29, 1831-1842.

DeMets, C., Dixon, T.H., 1999. New kinematic models for Pacific-North America motion from $3 \mathrm{Ma}$ to present. I: Evidence for steady motion and biases in the NUVEL-1A model. Geophysical Research Letters 26, 1921-1924.

Demets, C., Gordon, R.G., Argus, D.F., Stein, S., 1994. Effect of recent revisions to the geomagnetic reversal time-scale on estimates of current plate motions. Geophysical Research Letters 21, 2191-2194.

Dillon, J.T., Ehrig, P.L., 1993. Displacement of the Southern San Andreas fault. In: Ehrig, P.R., Weldon II, R.J., Matti, J.C. (Eds.), The San Andreas Fault System: Displacement, Palinspastic Reconstruction, and Geological Evolution. Geological Society of America, pp. 199-216.

Du, Y.J., Aydin, A., 1995. Shear fracture patterns and connectivity at geometric complexities along strike-slip faults. Journal of Geophysical Research-Solid Earth 100, 18093-18102.

Duan, B., Oglesby, D.D., 2007. Nonuniform prestress from prior earthquakes and the effect on dynamics of branched fault systems. Journal of Geophysical ResearchSolid Earth 112, B05308.1-B05308.18.

Fletcher, H.J., Freymueller, J.T., 2003. New constraints on the motion of the Fairweather fault, Alaska, from GPS observations. Geophysical Research Letters 30, 1139.

Freeman, T.S., Heath, E.G., Guptill, P.D., Waggoner, J.T., 1992. Seismic hazard assessment - Newport Inglewood fault. In: Pipkin, B.W., Proctor, R.J.(Eds.), Engineering Practice in Southern California. Association of Engineering Geologists, pp. 211-231.

Freund, R., 1974. Kinematics of transform and transcurrent faults. Tectonophysics 21, 93-134.

Garfunkel, Z., Ron, H., 1985. Block rotation and deformation by strike-slip faults. 2. The properties of a type of macroscopic discontinuous deformation. Journal of Geophysical Research-Solid Earth and Planets 90, 8589-8602.

Gilbert, L., Scholz, C.H., Beavan, J., 1994. Strain localization along the San Andreas fault: consequences for loading mechanisms. Journal of Geophysical Research 99, 975-984.

Haeussler, P.J., 2009. Surface map of the 2002 M7.9 Denali fault earthquake, Alaska. US Geological Survey Data Series Report 422. http://pubs.usgs.gov/ds/422/.

Haeussler, P.J., Schwartz, D.P., Dawson, T.E., Stenner, H.D., Lienkaemper, J.J., Sherrod, B., Cinti, F.R., Montone, P., Craw, P.A., Crone, A.J., Personius, S.F., 2004. Surface rupture and slip distribution of the Denali and Totschunda faults in the 3 November 2002 M 7.9 earthquake, Alaska. Bulletin of the Seismological Society of America 94, S23-S52.

Hardebeck, J.L., Hauksson, E., 1999. Role of fluids in faulting inferred from stress field signatures. Science 285, 236-239.

Hardebeck, J.L., Hauksson, E., 2001. Crustal stress field in southern California and its implications for fault mechanics. Journal of Geophysical Research-Solid Earth 106, 21859-21882.

Jackson, J., Molnar, P., 1990. Active faulting and block rotations in the Western Transverse Ranges, California. Journal of Geophysical Research-Solid Earth and Planets 95, 22073-22087.

Jackson, J.A., 1987. Active normal faulting and crustal extension. In: Coward, M., Dewey, J., Hancock, P. (Eds.), Continental Extensional Tectonics. Blackwell, London, pp. 3-18.

Jaeger, J.C., Cook, N.G.W., 1976. Fundamentals of Rock Mechanics. Chapman and Hall, London.

Jones, L.M., 1988. Focal mechanisms and the state of stress on the San Andreas fault in Southern California. Journal of Geophysical Research 93, 8869-8892.

Kendrick, K.J., Morton, D.M., Wells, S.G., Simpson, R.W., 2002. Spatial and temporal deformation along the northern San Jacinto fault, southern California: implications for slip rates. Bulletin of the Seismological Society of America 92, 2782-2802.

Kim, Y.S., Sanderson, D.J., 2006. Structural similarity and variety at the tips in a wide range of strike-slip faults: a review. Terra Nova 18, 330-344.

Kostrov, B.V., Das, S., 1984. Evaluation of stress and displacement-fields due to an elliptical plane shear crack. Geophysical Journal of the Royal Astronomical Society 78, 19-33.

Kranz, R.L., 1980. The effects of confining pressure and stress difference on static fatigue of granite. Journal of Geophysical Research 85, 1854-1866.

Little, T.A., Jones, A., 1998. Seven million years of strike-slip and related off-fault deformation, northeastern Marlborough fault system, South Island, New Zealand. Tectonics 17, 285-302.

Luyendyk, B.P., Kamerling, M.J., Terres, R.R., Hornafius, J.S., 1985. Simple shear of Southern-California during neogene time suggested by paleomagnetic decli- nations. Journal of Geophysical Research-Solid Earth and Planets 90, 2454-2466.

Magistrale, H., Rockwell, T., 1996. The central and southern Elsinore fault zone, Southern California. Bulletin of the Seismological Society of America 86, 1793 1803.

Mann, P., 2007. Global catalogue, classification, and tectonic origins of restraining and releasing bends on active and ancient strike-slip fault systems. In: Cunningham, W.D., Mann, P. (Eds.), Tectonics of Strike-slip Restraining and Releasing Bends. The Geological Society, London, pp. 13-142.

Martel, S.J., 1999. Mechanical controls on fault geometry. Journal of Structural Geology 21, 585-596.

Martel, S.J., Boger, W.A., 1998. Geometry and mechanics of secondary fracturing around small three-dimensional faults in granitic rock. Journal of Geophysical Research-Solid Earth 103, 21299-21314.

Meade, B.J., Hager, B.H., 2005. Block models of crustal motion in southern California constrained by GPS measurements. Journal of Geophysical Research-Solid Earth 110 B03403.1-B03403.

Morton, D.M., Matti, J.C., 1993. Extension and contraction within and evolving divergent strike-slip fault complex: the San Andreas and San Jacinto fault zones and their convergence in Southern California. In: Powell, R.E., Welden, R.J., Matti, J. (Eds.), The San Andreas Fault System: Displacement, Palinspastic Reconstruction, and Geological Evolution, Memoir 178. Geological Society of America, Boulder, CO, pp. 217-230.

Park, J.O., Tsuru, T., Kodaira, S., Cummins, P.R., Kaneda, Y., 2002. Splay fault branching along the Nankai subduction zone. Science 297, 1157-1160.

Plafker, G., 1965. Tectonic deformation associated with 1964 Alaska earthquake earthquake of 27 March 1964 resulted in observable crustal deformation of unprecedented areal extent. Science 148, 1675-1687.

Poliakov, A.N.B., Dmowska, R., Rice, J.R., 2002. Dynamic shear rupture interactions with fault bends and off-axis secondary faulting. Journal of Geophysical Research-Solid Earth 107, ESE6.1-ESE6.18.

Savage, J.C., Burford, R.O., 1973. Geodetic determination of relative plate motion in Central California. Journal of Geophysical Research 78, 832-845.

Scholz, C.H., 1977. Transform fault systems of California and New Zealand: similarities in their tectonic and seismic styles. Journal of the Geological Society London 133, 215-229.

Scholz, C.H., 1988. The brittle-plastic transition and the depth of seismic faulting. Geologische Rundschau 77, 319-328.

Scholz, C.H., 2000. Evidence for a strong San Andreas fault. Geology 28, 163-166.

Scholz, C.H., Barazangi, M., Sbar, M.L., 1971. Late Cenozoic evolution of the Great Basin, westem United States, as an ensialic interarc basin. Geological Society of America Bulletin 82, 2979-2990.

Scholz, C.H., Gupta, A., 2000. Fault interactions and seismic hazard. Journal of Geodynamics 29, 459-467.

Sibson, R.H., 1985. A note on fault reactivation. Journal of Structural Geology 7, 751-754.

Sibson, R.H., Xie, G.Y., 1998. Dip range for intracontinental reverse fault ruptures: truth not stranger than friction? Bulletin of the Seismological Society of America 88, 1014-1022.

Stein, R.S., 1999. The role of stress transfer in earthquake occurrence. Nature 402 605-609.

Stephenson, W.J., Odum, J.K., Williams, R.A., Anderson, M.L., 2002. Delineation of faulting and basin geometry along a seismic reflection transect in urbanized San Bernardino Valley, California. Bulletin of the Seismological Society of America 92, 2504-2520.

Suppe, J., 2007. Absolute fault and crustal strength from wedge tapers. Geology 35 , 1127-1130.

Townend, J., Zoback, M.D., 2000. How faulting keeps the crust strong. Geology 28, 399-402.

Wakabayashi, J., 1999. Distribution of displacement on and evolution of a young transform fault system: the northern San Andreas fault system, California. Tectonics 18, 1245-1274.

Walcott, R.I. 1998. Modes of oblique compression: late Cenozoic tectonics of the South Island of New Zealand. Reviews of Geophysics 36, 1-26.

Wesnousky, S., 1986. Earthquakes, quaternary faults, and seismic hazard in California. Journal of Geophysical Research 91, 12587-12631.

Yeats, R., Berryman, K., 1987. South Island, New Zealand and Transverse Ranges, California, a seismotectonic comparison. Tectonics 6, 363-376.

Zoback, M.L., Zoback, M.D., 2007. Lithospheric stress and deformation. In Watts, A.B. (Ed.), Treatise on Geophysics. Elsevier, Amsterdam, pp. 253-274. 